\title{
Deposition of gold nanoparticles on titanium nanopits
}

\author{
Marek P. Kobylański, Zuzanna Juchno, Mateusz A. Baluk, Adriana Zaleska-Medynska \\ Department of Environmental Technology, Faculty of Chemistry, University of Gdansk, Wita Stwosza 63, Gdansk, Poland
}

Corresponding author: marek.kobylanski@phdstud.ug.edu.pl

DOI: 10.31708/spi3.18/kobyl.cns18

\section{Introduction}

A necessity to obtain a new matrix for metal nanoparticles or quantum dots require to develop materials, which dimension could be easily controlled. The $\mathrm{TiO} 2$ nanotubes obtained via anodic oxidation of a titanium foil could be easily produced and their synthesis conditions as electrolyte composition, applied voltage, time of anodization directly influence on their dimension (Kobylański et al., 2018). Utilizing the surface of titanium created after removing of the NTs allow to obtain pits, which could be a space for deposited nanoparticles. Subsequently, it is possible to deposit the gold nanoparticles from their precursor by photodeposition or spin-coating method and finally, obtain the titanium matrix with the nanoparticles. The shape of gold nanoparticles depends on the experiment condition, but it is possible to obtain the triangle structures of gold (Carville, Neumayer, Manzo, Gallo, \& Rodriguez, 2016; Ng, Razak, Aziz, \& Cheong, 2014).

\section{Materials and Methods}

The procedure od fabrication of nanopits include synthesis of $\mathrm{TiO} 2$ nanotubes via anodic oxidation, removing of the $\mathrm{TiO} 2$ nanotube arrays in ultrasonic bath, subsequent anodization and dissolution of nanotubes in oxalic acid. Finally, the nanoparticles of gold was deposited on the surface of titanium by photodeposition of gold nanoparticles from the precursor - $0.05 \mathrm{M}$ of chloride gold (III) solution in isopropanol. The light source was a $250 \mathrm{~W}$ Xenon lamp under. The nanoparticles deposited using spin-coater was obtained from the same solution. The solution in the range of 100-500 $\mu \mathrm{l}$ was dropped on the center of titanium foil, subsequently the layer was coated with rotational speed $1500 \mathrm{rpm}$. Then, samples was dried at $80^{\circ} \mathrm{C}$ and calcined for $10 \mathrm{~min}$ in 450 ${ }^{\circ} \mathrm{C}$.

\section{Results}

Figure 1 shows the SEM images of gold nanoparticles deposited on titanium pits. It could be concluded that samples obtained from photodeposition (Figure 1a) characterized irregular shape and size in contrast to utilize spin-coater (Figure 1b).
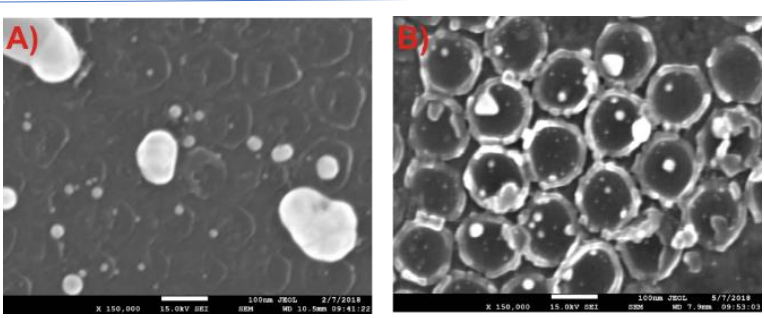

Figure 1. SEM images of gold nanoparticles deposited on the titanium surface by: a) photodeposition, b) spin-coating method.

\section{Discussion}

Based on the comparison of the SEM images it could be concluded that nanoparticles obtained by spin-coating method allow to obtain the nanoparticles which size is more regular than for materials fabricated via photodeposition method. Moreover, by utilizing spincoating method it is possible to obtain triangle nanostructured of gold. The size of the gold nanoparticles is in the range $5-20 \mathrm{~nm}$, however, the nanoparticles is loaded inside the pits as well as on their walls. Based on the all obtained results it could be concluded, that pits fabricated from dissolution of $\mathrm{TiO} 2$ nanotubes could be a good matrix for deposition of gold nanoparticles. These kind of materials could be applied in the sensor for chemical substances.

\section{Acknowledgments}

This research was financially support by BMN No. 5388620-B751-18.

\section{References}

Carville, N. C., Neumayer, S. M., Manzo, M., Gallo, K., \& Rodriguez, B. J. (2016). Biocompatible Gold Nanoparticle Arrays Photodeposited on Periodically Proton Exchanged Lithium Niobate. ACS Biomaterials Science and Engineering, 2(8), 1351-1356.

https://doi.org/10.1021/acsbiomaterials.6b00264

Kobylański, M. P., Mazierski, P., Malankowska, A., Kozak, M., Diak, M., Winiarski, M. J., ... ZaleskaMedynska, A. (2018). TiO2-CoxOycomposite nanotube arrays via one step electrochemical anodization for visible light-induced photocatalytic reaction. Surfaces and Interfaces, 12, 179-189. https://doi.org/10.1016/j.surfin.2018.06.001

Ng, S. A., Razak, K. A., Aziz, A. A., \& Cheong, K. Y. (2014). The effect of size and shape of gold 
nanoparticles on thin film properties. Journal of Experimental Nanoscience, 9(1), 64-77.

https://doi.org/10.1080/17458080.2013.813651 